\title{
Adolescents Exposure to Global Mass Media: Influences on Sexual Behavior and Sexuality in Hawassa City, Ethiopia
}

\author{
Tewodros Habtegiorgis Zikarge \\ Wolaita Sodo University, Department of Sociology, SNNPR, Ethiopia
}

\begin{abstract}
Over the past decade, new research has identified media as having the potential to serve both roles Brown JD (2007). Much of this work focuses on traditional media, such as television, film, music, and magazines. But the media landscape is evolving at a startling pace, and a greater diversity of content, new types of media, and new platforms for delivering media are constantly emerging. This study had largely tried to address the gaps in addressing the youth's problematic sexual behavior arising from uncontrolled media influence. The study employed cross-sectional survey design so as to obtain information about the present situation which is related to the issue under study. It utilized both quantitative and qualitative methods of data collection and analysis to obtain the strengths from both methods and to address their weakness by using strengths from each other. While survey questionnaire was utilized as technique of collecting quantitative data, the qualitative was collected using interview, FGD and observation. Under the implementation of simple random technique, 40 sample students have been selected ( 20 female and 20 male) students. Through a detail investigation the analyzed data dictates that though media used as a source of entertainment, information, sensation and coping gender role modeling, and youth culture identification are the negative effects. In terms of exposure, adolescent respondents spent almost 3-4 hours of the day using media with the most time spent watching television and visiting websites. Case respondents also use print media put the fact remains the same that there exist large individual variations in adolescent media use. Even if there is minor positive media influence, largely there exist negative aspects of consumption of media side of side with its advantage. Though, the function of televisions, Internet and other mass media include providing information and entertainment as well as a portrait of the world beyond the immediate context in which they live however, one negative aspect of this medias is that it involves passive learning. Special concerns are the ways sexual contents, aggression are portrayed on television and other massmedias. Therefore, from the finding of the study it can be recommended as first it's important to encourage socially responsible programming second; Mass Medias should have to regulate themselves in regard to their influence adolescents and finally, encourage media literacy programs as part of school curricula, youth and community organizations.
\end{abstract}

Keywords: Adolescents, Sexual Behaviors, Sexuality, Mass Media

DOI: $10.7176 /$ RHSS/9-17-03

Publication date:September $30^{\text {th }} 2019$

\section{I.Introduction}

Among the major Socio-economic problems of developing countries, young adult's problem accounts the large proportion (Jeanne, 1992). Adolescence is the developmental period of transition between childhood and adulthood. In most cultures adolescence begin at approximately 10 to 13 of age and ends at about 18 to 22 years of age. Adolescent's development takes place in social context which provide the setting and socio-cultural backgrounds for physical, cognitive and socio-emotional growth. These days the wellbeing of adolescents is one of the most important concerns. Every one cherishes the futures of adolescents for they are the future of any society. Studies indicate that some adolescents in USA and majority of adolescents found in third world countries are not reaching their potential because they are not being adequately instructed in school and not being adequately supported by the society at large. (Santrock, 2005:25)

Adolescents who don't reach their full potential and don't grow up to make competent contribution to their world in variably have not been given adequate individual attention and support as they were growing up. According to the studies, adolescents need parents who love them; monitor their development; who are sensitive to their needs, which have a sound understanding of their own, as well as their adolescent's development and help to steer them away from health compromising behaviors. In addition to these other agents of socialization are highly influential in the development of adolescent's identity. The early history reveals the distinguishing features of adolescents that should be understood and work with to bring healthy adolescents in a society (Santrock 2005:7-9).

Today's world is highly characterized by rapid globalization and global change. The advancement in transportation and telecommunication is merging the world into a single large system. Similar life styles across the world and emergence of global culture have become inevitable features of present time. Brown JD, Greenberg BS \& Buerkel-Rothfuss NL. (1993).

Alike to those of western adolescents, Ethiopians are believed to be challenged by the contradictory and 
powerful message transmitted by mainly electronic medias which most of the time preach the western cultures and those adolescents brought up or live in a setting where there is people with diverse cultures having number of values, norms, attitudes and lifestyles also in a setting characterized by dynamic population composition are believed to fall in confusion to choose among the aforementioned alternatives provided in their setting (Ethiopian Herald, 1999).

Since social context have a major and most important role in the development of adolescents, the study had addressed the unnoticed problems of adolescents emerging from their exposure to the global media affecting their sexual behavior with in the social contexts which reinforce the existing socio-economic and political wellbeing of the country. Adolescence's sexual wellbeing depends on their sexual experience attitudes and behaviors that are constructed on and largely shaped by parental control peer group influence societal norms, neighborhood setting and recently by the influence of media (Ethiopian Herald, 1999).

Human development is commonly described in terms of periods. Adolescence is the period that lies between childhood and adulthood. Even if, many adolescents present in Hawassa there is no data in any organization which reflects high adult guidance and supervision. For reducing youth problematic sexual behavior, there is no or low number of youth centers and associates with adequate services and strict penalties on illegal videos, games, clips, movies and TV programs. Therefore, a great deal of research attention has been devoted to understand what puts adolescents at risk for these outcomes, given their enormous social, economic, and public health consequences (Maynard RA, 1997). Yet it is clear that we need to know more and do more to address risky sexual activity among youth. One route is through the identification of additional contributors to this behavior that have been understudied factors that put youth at risk and levers that can be used in preventive interventions. This paper had largely tried to address the gaps in addressing the youth's problematic sexual behavior arising from uncontrolled media influence.

Figure1: Mass media and related adolescent sexual problems

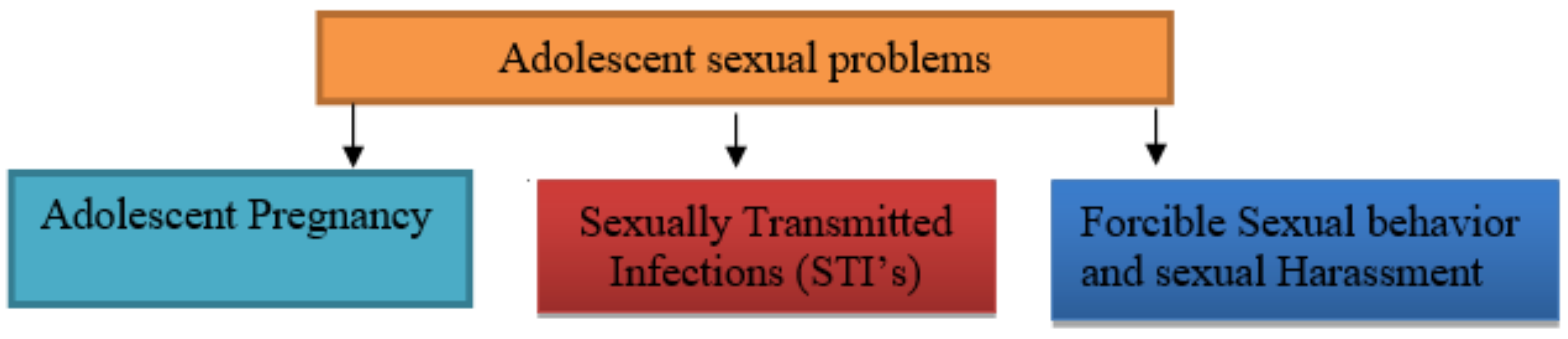

\section{Materials and Methods}

\section{a. Research Design}

The general principle of research design is that the research strategy or strategies, and the methods or techniques employed must be appropriate for the questions made the researcher wants to answer (Robson, 1993:39). This study employed, cross-sectional survey design so as to obtain information about the present situation which is related to the issue under study. Data's were collected at one point in time from randomly selected samples of the population. However, the cross sectional survey design was made to approximate longitudinal survey design, as questionnaire elements that refer to the past were included. That is, while the cross-sectional survey is used to obtain data regarding the purpose of adolescent's media attention and frequency of consumption, the approximating longitudinal survey is used to provide data relevant to their past situations.

\section{b. Methods of Data Collection}

This study, utilized both quantitative and qualitative methods of data collection and analysis to obtain the strengths from both methods and to address their weakness by using strengths from each other. It employed methodological triangulation of various methods of data collection and analysis in order to assure the validity and reliability of research results, and to effectively address different objectives of the research. While survey questionnaire was utilized as technique of collecting quantitative data, the qualitative was collected using interview, FGD and observation.

\section{c. Sampling Technique}

The sampling procedure of the study was simple random sampling technique. In a given study, representative sample data about the issue under study enhance the validity of the finding of the study. On this study, simple random sampling which is a type of probability sampling design was implemented in the selection of the sample element. This method provides equal and independent chance of selection for the whole elements of the target population. Under the implementation of this technique, 40 sample students have been selected (20 female and 20 male) students. 


\section{Results and Discussion}

A.Purpose of Adolescents media attention and frequency of consumption

Table 2: Frequency and Percentage Distribution of responding Adolescents by Sex and Reason for media attention

\begin{tabular}{|c|c|c|c|c|c|c|}
\hline \multirow[b]{3}{*}{ Purpose of Adolescents media attention } & \multicolumn{4}{|c|}{ Sex } & \multicolumn{2}{|c|}{ Total } \\
\hline & \multicolumn{2}{|c|}{ Male } & \multicolumn{2}{|c|}{ Female } & & \\
\hline & No & $\%$ & № & $\%$ & No & $\%$ \\
\hline Entertainment & 8 & 20 & 2 & 5 & 10 & 25 \\
\hline Information & 4 & 10 & 3 & 7.5 & 7 & 17.5 \\
\hline For intends stimulation & 7 & 17.5 & 3 & 7.5 & 10 & 25 \\
\hline Relive from anxiety \& unhappiness & 3 & 7.5 & 5 & 12.5 & 8 & 20 \\
\hline For being connected to a larger peer network and culture & 4 & 10 & 1 & 2.5 & 5 & 12.5 \\
\hline Total & 26 & 65 & 14 & 35 & 40 & 100 \\
\hline
\end{tabular}

The persuasion capabilities of mass-medias are staggering. Many of contemporary adolescents have spent more time sitting in front of a television set than with their parents or in class room. In addition to television, radios, CDs, and music videos are other Medias that had immense influences in the lives of many adolescent. As indicated in the above table, about $8(20 \%)$ and $2(5 \%)$ of the male and female respondents respectively attend medias for the purpose of entertainment and an enjoyable diversion become their everyday concern, whereas About 3(7.5\%) and 5(12.5\%) of men and women adolescents respectively consume media for the sake of seeking pleasure and relief. about $7(17.5 \%)$ and $3(7.5 \%)$ of men and women respondents respectively replied that it's because for intense stimulation that appeals to adolescents they are attending medias and about $4(10 \%)$ and $3(7.5 \%)$ of the adolescent men and women respondents point it's for information purpose that they majorly attend medias the rest few adolescent about $4(10 \%)$ and $1(2.5 \%)$ responded that it's for being connected to a larger peer network and culture which is conveyed through adolescent oriented media that they are majorly attending global mass medias.

Table 3: Frequency and Percentage Distribution of responding Adolescents by Sex, Television and Internet Consumption

\begin{tabular}{|c|c|c|c|c|c|c|c|}
\hline \multirow{6}{*}{$\begin{array}{l}\text { Do you attend TV } \\
\text { Programs? }\end{array}$} & \multirow{4}{*}{$\begin{array}{l}\text { Alternatives } \\
\text { Yes }\end{array}$} & \multicolumn{4}{|c|}{ Sex } & \multirow{2}{*}{\multicolumn{2}{|c|}{ Total }} \\
\hline & & \multicolumn{2}{|l|}{ Male } & \multicolumn{2}{|c|}{ Female } & & \\
\hline & & № & $\%$ & No & $\%$ & No & $\%$ \\
\hline & & 25 & 62.5 & $1 \overline{5}$ & 37.5 & 40 & 100 \\
\hline & No & - & - & - & - & - & - \\
\hline & Total & 25 & 62.5 & 15 & 37.5 & 40 & 100 \\
\hline \multirow{4}{*}{$\begin{array}{l}\text { Days you spent attending } \\
\text { TV programs per week }\end{array}$} & $5-7$ days & 13 & 32.5 & 20 & 50 & 33 & 82.5 \\
\hline & 2-4 days & 3 & 7.5 & 2 & 5 & 5 & 12.5 \\
\hline & 1 day & - & - & 2 & 5 & 2 & 5 \\
\hline & Total & 16 & 40 & 24 & 60 & 40 & 100 \\
\hline \multirow{5}{*}{$\begin{array}{l}\text { Preferred kind of media } \\
\text { packages most attended by } \\
\text { adolescents }\end{array}$} & News content & 3 & 7.5 & 5 & 12.5 & 8 & 20 \\
\hline & Entertainment & 4 & 10 & 2 & 5 & 6 & 15 \\
\hline & Programs with sexual contents & 10 & 25 & 15 & 37.5 & 25 & 62.5 \\
\hline & Others & - & - & 1 & 2.5 & 1 & 2.5 \\
\hline & Total & 17 & 42.5 & 23 & 57.5 & 40 & 100 \\
\hline \multirow{3}{*}{$\begin{array}{l}\text { Are you consumer of } \\
\text { internet services? }\end{array}$} & Yes & 18 & 45 & 22 & 55 & 40 & 100 \\
\hline & No & - & - & - & - & - & - \\
\hline & Total & 18 & 45 & 22 & 55 & 40 & 100 \\
\hline \multirow{6}{*}{$\begin{array}{l}\text { Preferred kinds of } \\
\text { websites most visited by } \\
\text { adolescents }\end{array}$} & Sex-oriented & 10 & 25 & 8 & 20 & 18 & 45 \\
\hline & e-mail & 5 & 12.5 & 4 & 10 & 9 & 22.5 \\
\hline & Chat rooms & 2 & 5 & 4 & 10 & 6 & 15 \\
\hline & Sites promoting up-to-date news & 1 & 2.5 & - & - & 1 & 2.5 \\
\hline & Entertainment oriented & 3 & 7.5 & 3 & 7.5 & 6 & 15 \\
\hline & Total & 21 & 52.5 & 19 & 47.5 & 40 & 100 \\
\hline \multirow{5}{*}{$\begin{array}{l}\text { Hours adolescents spent } \\
\text { visiting preferred websites } \\
\text { per day }\end{array}$} & 1-3 hours & 13 & 32.5 & 17 & 42.5 & 30 & 75 \\
\hline & 3-5 hours & 3 & 7.5 & 2 & 5 & 5 & 12.5 \\
\hline & $5-8$ hours & 1 & 2.5 & 1 & 2.5 & 2 & 5 \\
\hline & Above 8 hours & 2 & 5 & 1 & 2.5 & 3 & 7.5 \\
\hline & Total & 19 & 47.5 & 21 & 52.5 & 40 & 100 \\
\hline
\end{tabular}

A number of lessons emerge from these data. Among them is the finding that television content still 
dominates the media landscape. While new media combined are taking up more and more of teens' time and television programming is increasingly being viewed on platforms other than a traditional set, television is still, by far, the most central aspect of adolescents' media lives. No other activity comes close in terms of time spent with a particular form of content or a particular platform. In terms of time spent online, YouTube, game playing, and social networking sites are the key activities and are equal-attention grabbers for youth, though as we will note below, they have not been equally attended to by researchers. Cell phones are increasingly the platform of choice: When time spent texting and talking is included in estimates, teens spend more time with them than with computers and use them for a full range of activities. Cell phones are used for listening to music, watching television content, and playing games (when combined) more than for talking. Text messaging is not yet the preferred mode of phone communication for the majority of youth, but among those who use it, it is vastly preferred over talking.

Though largely expected, some other patterns are also apparent and should be emphasized. First, a substantial portion of the time spent with newer media involves creating content and interacting with others posting comments and information on social networking sites and looking at or posting video on YouTube. Second, platform and content are increasingly independent.

A large amount of "television" is watched on something other than a set. As the technology and software to use the Internet on television sets becomes available, shifts may occur in this direction as well, such that televisions become the preferred mode of listening to music, browsing online, or communicating with friends. Thus, it will be critical to think about both platform and content in exploring media effects and developing interventions related to sexual health, and to make no assumptions about how or where a particular form of content will be consumed. Finally, we note that the use of new media spans racial/ethnic and gender boundaries, though there are small gender differences in the use of video and online games, somewhat lower rates of cell phone ownership among the youngest teens, and somewhat less game playing among older teens. As with traditional media, the rates of many forms of new media use are somewhat higher in the minority groups that are at higher risk for teen pregnancy and STIs. Thus, there is much potential to reach these groups with interventions, as well as some potential for negative effects of exposure.

Table 4: Frequency and Percentage Distribution of responding Adolescents by Sex and Print Media

Consumption

\begin{tabular}{|c|c|c|c|c|c|c|c|}
\hline \multirow[t]{3}{*}{ Item } & \multirow[t]{3}{*}{ Alternatives } & \multicolumn{4}{|c|}{ Sex } & \multicolumn{2}{|c|}{ Total } \\
\hline & & \multicolumn{2}{|c|}{ Male } & \multicolumn{2}{|c|}{ Female } & & \\
\hline & & No & $\%$ & No & $\%$ & No & $\%$ \\
\hline \multirow{3}{*}{$\begin{array}{l}\text { Are you consumer of print } \\
\text { medias, like magazines, } \\
\text { newspapers etc.? }\end{array}$} & Yes & 15 & 37.5 & 10 & 25 & 25 & 62.5 \\
\hline & No & 10 & 25 & 5 & 12.5 & 15 & 37.5 \\
\hline & Total & 25 & 62.5 & 15 & 37.5 & 40 & 100 \\
\hline \multirow{4}{*}{$\begin{array}{l}\text { Time you spent by reading } \\
\text { the above medias }\end{array}$} & Daily & - & - & - & - & - & - \\
\hline & Twice a week & 10 & 25 & 12 & 30 & 22 & 55 \\
\hline & Once a month & 6 & 15 & 12 & 30 & 18 & 45 \\
\hline & Total & 16 & 40 & 24 & 60 & 40 & 100 \\
\hline \multirow{5}{*}{$\begin{array}{l}\text { The content or kinds of } \\
\text { print media most chosen } \\
\text { by adolescents }\end{array}$} & Sport magazines & 10 & 25 & 2 & 5 & 12 & 30 \\
\hline & News papers & 1 & 2.5 & 1 & 2.5 & 2 & 5 \\
\hline & Non-school books & 3 & 7.5 & 5 & 12.5 & 8 & 20 \\
\hline & Romantic or comic & 6 & 15 & 12 & 30 & 18 & 45 \\
\hline & Total & 20 & 50 & 20 & 50 & 40 & 100 \\
\hline
\end{tabular}

Consumption of print Medias such as magazines, newspapers, academic books, and non-academic books etc. gradually increase during adolescence age. About $62.5 \%$ of which $10(25 \%)$ and $15(37.5 \%)$ female and male respondents respectively use print medias. Twice a week and $6(15 \%)$ and $12(30 \%)$ of men and women respondents respectively replay they attend this medias once a month. Though in the country where reading habit is much more backward, our case target adolescents show a slight step ahead while reading culture still remains back warded.

\section{B.Media consumption and influences on adolescents sexual behavior}

Adolescents have almost instable curiosity about the mysteries of sex. They wonder whether they are sexually attractive, how to behave sexually, and what the future holds for their sexual life. Most adolescents eventually manage to develop a mature sexual identity, even though, as adults can attest, there are always times of vulnerability and confusion along life's sexual journey. Much of what we hear about adolescent sexually involves problems, such as adolescent pregnancy and sexually transmitted infections. The table below indicates the consumption of media and influences on adolescent's sexual behavior. 
Table 5: Frequency and Percentage Distribution of responding Adolescents by Sex and Sexual Behavior

\begin{tabular}{|c|c|c|c|c|c|c|c|}
\hline \multirow[t]{3}{*}{ Item } & \multirow[t]{3}{*}{ Alternative } & \multicolumn{4}{|c|}{ Sex } & \multicolumn{2}{|r|}{ Total } \\
\hline & & \multicolumn{2}{|c|}{ Male } & \multicolumn{2}{|c|}{ Female } & \multirow{2}{*}{ No } & \multirow[t]{2}{*}{$\%$} \\
\hline & & No & $\%$ & No & $\%$ & & \\
\hline \multirow[t]{5}{*}{ Do you have a girl/ boy friend } & Yes & 12 & 30 & 6 & 15 & 18 & 45 \\
\hline & Used to have & 7 & 17.5 & 3 & 7.5 & 10 & 25 \\
\hline & On the way to have & 4 & 10 & 3 & 7.5 & 7 & 17.5 \\
\hline & No & 1 & 2.5 & 4 & 10 & 5 & 12.5 \\
\hline & Total & 24 & 60 & 16 & 40 & 40 & 100 \\
\hline \multirow[t]{3}{*}{ Have you ever had a sex } & Yes & 18 & 45 & 12 & 30 & 30 & 75 \\
\hline & No & 4 & 10 & 6 & 15 & 10 & 25 \\
\hline & Total & 22 & 55 & 18 & 45 & 40 & 100 \\
\hline \multirow{3}{*}{$\begin{array}{l}\text { Did you use contraceptives in your } \\
\text { first sex }\end{array}$} & Yes & 7 & 17.5 & 6 & 15 & 13 & 32.5 \\
\hline & No & 10 & 25 & 7 & 17.5 & 17 & 42.5 \\
\hline & Total & 17 & 42.5 & 13 & 32.5 & 30 & 75 \\
\hline
\end{tabular}

From the adolescents who replied, about 12(30\%) and 6(15\%) men and women respectively had a boy /girlfriend. And about 7(17.5\%) and 3(7.5\%) of men and women respectively used to have, and about $4(10 \%)$ men and women respondents respectively are on the way to this relation. But only $1(2.5 \%)$ and $4(10 \%)$ of men and women respondents respectively replied they have none of this relation at all.

From the total about $18(45 \%)$ and $12(30 \%)$ of men and women respondents respectively imply they had sex with in their life time. But about $4(10 \%)$ and $6(15 \%)$ of main and women respondents respectively imply they had never been engaged in sexual activities. From those who engaged in sex about $7(17.5 \%)$ and $6(15 \%)$ of men and women respectively did use contraceptives in their first sex, unlike $10(25 \%)$ and $7(17.5 \%)$ of male and female respondents respectively did not use contraceptives while they engage in their first sex.

\section{C.Mass media and related adolescent sexual problems}

Early intercourse appears to be part of a cluster of adolescent problem behaviors. It correlates with substance use, truancy, and aggression and is also well predicted by indicators of behavioral deviance. Intercourse at any age places an individual at risk for pregnancy and at greater risk for STIs. But early intercourse initiation poses special risks, with an increase in the odds of both pregnancy and STIs when it occurs at a younger age.

Table 6: Frequency and Percentage Distribution of responding Adolescents by related sexual problems

\begin{tabular}{|c|c|c|c|c|c|c|}
\hline \multirow{3}{*}{ Adolescent sexual problems } & \multicolumn{4}{|c|}{ Sex } & \multicolumn{2}{|c|}{ Total } \\
\hline & \multicolumn{2}{|c|}{ Male } & \multicolumn{2}{|c|}{ Female } & \multirow[b]{2}{*}{ № } & \multirow[b]{2}{*}{$\%$} \\
\hline & No & $\%$ & No & $\%$ & & \\
\hline Unwanted Pregnancy & - & - & 10 & 25 & 10 & 25 \\
\hline Sexually Transmitted Infections (STI's) & 4 & 10 & 2 & 5 & 6 & 15 \\
\hline Forcible Sexual behavior and sexual Harassment & 5 & 12.5 & 10 & 25 & 15 & 37.5 \\
\hline Others(such as early intercourse initiation) & 6 & 15 & 3 & 7.5 & 9 & 22.5 \\
\hline Total & 40 & 50 & 100 & 50 & 40 & 100 \\
\hline
\end{tabular}

The above table 6 indicates the distribution of mass media and related adolescent sexual problems. As it has been displayed below, $37.5 \%$ of the respondents are exposed for forcible sexual behaviors and sexual harassment, where as $25 \%$ of female respondents were exposed for unwanted pregnancy and $15 \%$ of them were caught by sexually transmitted Infections. 


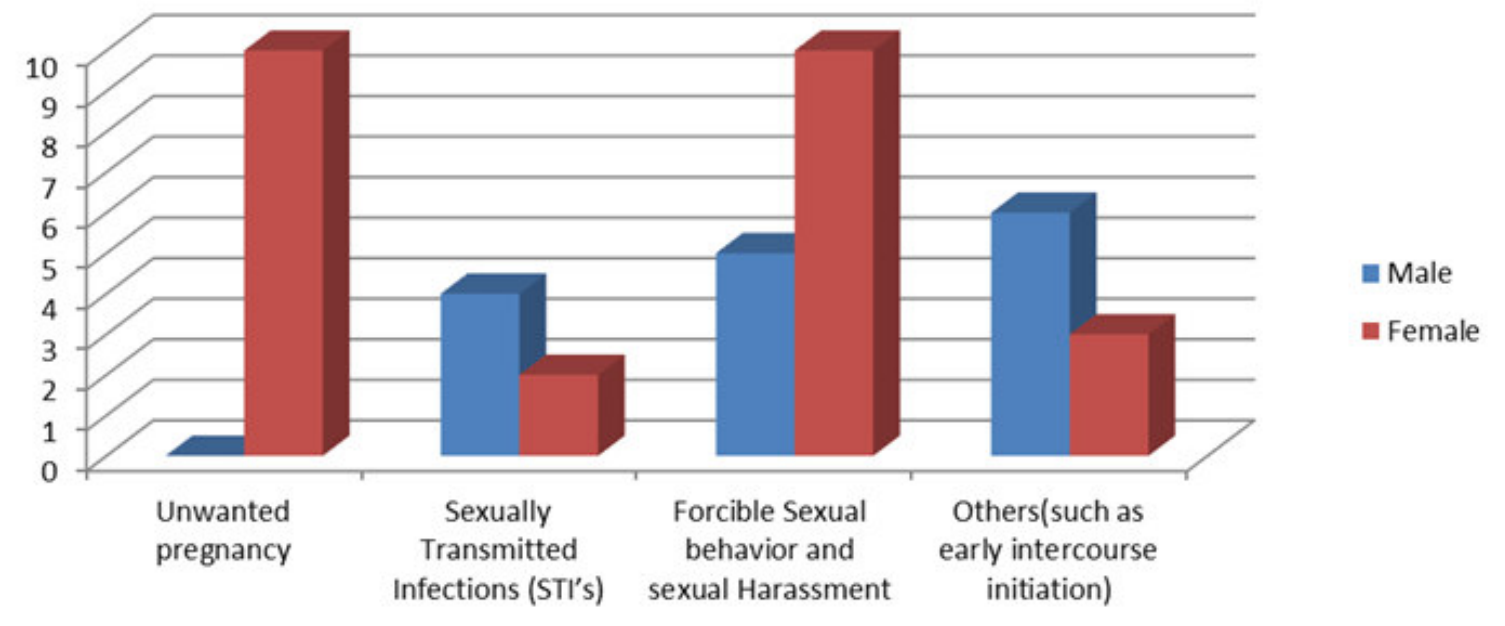

Fig.1: Adolescents' sexual problems by sex

\section{Conclusion}

Adolescents are exposed to many sexual images and messages on television that are almost universally presented in a positive light with little discussion of potential risks and adverse consequences. They use the media as sources of information about sex, drugs, AIDS, and violence as well as to learn to behave in relationships.

Apart from negative adolescent exposure to global mass media, on the positive side, many adolescents have learned something positive from sexual scenes on media. Such as how to say no on sexual situation that makes them uncomfortable and how to take a partner about safer sex. The overall conclusion about adolescent exposure to global mass media is in contrary. The overall evidence indicates that frequent and involved exposure to sexually oriented media such as sex oriented music videos and movies are more enjoyable than extracting the sweet from it.

Though media used as a source of entertainment, information, sensation and coping gender role modeling, and youth culture identification are the negative effects. In terms of exposure, adolescent respondents spent almost 3-4 hours of the day using media with the most time spent watching television and visiting websites. Case respondents also use print media put the fact remains the same that there exist large individual variations in adolescent media use.

Even if there is minor positive media influence, largely there exist negative aspects of consumption of media side of side with its advantage. Though, the function of televisions, Internet and other mass media include providing information and entertainment as well as a portrait of the world beyond the immediate context in which they live however, one negative aspect of this Medias is that it involves passive learning. Special concerns are the ways sexual contents, aggression are portrayed on television and other Mass Medias.

While Sexual activities are a healthy behavior which is necessary for procreation, carries with it considerable risks if appropriate safeguards are not taken. Adolescents encounter two kinds of risks, unintended unwanted pregnancy y and sexually transmitted infections. A large proportion of adolescents which is about $17(42.5 \%)$ did not use contraceptives while engaging in their first sex.

\section{Recommendation}

1. It's important to encourage socially responsible programming. There is good evidence of a link between media and adolescent problematic sexual behavior. The media also shape many other dimensions of adolescent's development gender, ethnic and standards of beauty, family life, and sexuality. Writers, producers and mass media executives need to recognize how power full their message are to adolescents and work with experts on adolescent development to provide more positive images on adolescents.

2. Support public efforts to make media more adolescent friendly. Mass Medias should have to regulate themselves in regard to their influence adolescents, like western nations Irrespective of USA have stronger regulations to faster appropriate educational programming.

3. Encourage media literacy programs as part of school curricula, youth and community organizations, and family life many adolescents do not have the knowledge and skills to critically analyze media messages. Media literacy programs should focus not only on television, but also on internet, newspapers, magazines, radio, videos, music, and electronic games. 


\section{References}

1. Baxter RL, De Riemer C, Landini A, et al. A content analysis of music videos. J Broadcast Electronic Media 1985; 29: 333-340.

2. Brown JD, Greenberg BS, Buerkel-Rothfuss NL. Mass media, sex, and sexuality. Adolescence Med 1993;4(pt 1): 511-552.

3. Brown JD, Steele JR. Sex and the mass media. Menlo Park (CA): Kaiser Family Foundation; 1995.

4. Buerkel-Rothfuss NL, Strouse JS, Pettey G, et al. Adolescents' and young adults' exposure to sexually oriented and sexually explicit media. In: Greenberg BS, Brown JD, Buerkel-Rothfuss NL, eds. Media, sex and the adolescent. Cresskill (NJ): Hampton Press; 1993: 99-112.

5. Bruce M.King. Human sexuality .1996. Joday prentice hall press. USA

6. Centers for Disease Control and Prevention (CDC). Current trends in premarital sexual experience among adolescent women-United States, 1970-1988. MMWR Morb Mortal Wkly Rep 1991; 39(51-52): 929-932. [PubMed]

7. Committee on Communications, American Academy of Pediatrics. Sexuality, contraception and the media. Pediatrics 1995; 95: 298-300.

8. Erik H. Erikson. Youth Change and Challenge. 1963. New York. Basic Books Inc.

9. Greenberg BS, Stanley C, Siemicki M, et al. Sex content on soaps and prime-time television series most viewed by adolescents. In: Greenberg BS, Brown JD, Buerkel- Rothfuss NL, eds. Media, sex and the adolescent. Cresskill (NJ): Hampton Press; 1993: 29-44.

10. Hofferth SL, Kahn JR, Baldwin W. Premarital sexual activity among U.S. teenage women over the past three decades. Fam Plann Perspect 1987; 19: 46-53. [PubMed]

11. Huston AC, Wartella E, Donnerstein E. measuring the effects of sexual content in the media: a report to the Kaiser Family Foundation. Menlo Park (CA): Kaiser Family Foundation; 1998.

12. John W. Santrock. Adolescence 2005. $10^{\text {th }}$ Ed. McGraw-Hill Companies, Boston, MA.

13. Kaiser Family Foundation/Children Now. Talking with kids about tough issues: a national survey of parents and kids. Menlo Park (CA): Kaiser Family Foundation; 1999.

14. Kunkel D, Cope KM, Maynard-Farinola WJ, et al. Sex on TV: content and context. Menlo Park (CA): Kaiser Family Foundation; 1999.

15. Louis Harris \& Associates, Inc. Sexual material on American network television during the 1987-88 seasons. New York (NY): Planned Parenthood Federation of America; 1988.

16. Lowry DT, Towles DE. Prime time TV portrayals of sex, contraception, and venereal diseases. Journalism Q 1989;66: 347-352.

17. Lowry DT, Towles DE. Soap opera portrayals of sex, contraception, and sexually transmitted diseases. J Commun 1989; 39: 76-83.

18. Roberts DF, Foehr UG, Rideout VJ, et al. Kids \& media at the new millennium. Menlo Park (CA): Kaiser Family Foundation; 1999.

19. The Ethiopian herald. Focus on women's sexual harassment at work place. 2005. Addis Ababa, Ethiopia. 